interruption. Further, continuation of the same anti-TNF $\alpha$ did not cause relapse in some cases.

The underlying SpA was well controlled (ASDAS-CRP) when uveitis, patients being classified as responders compared to previous visit, suggesting paradoxical uveitis.

Conclusions: Although rare, new onset or flare of uveitis may occur during antiTNF therapy in axSpA. Surprisingly, not only TNF receptor but also monoclonal antibodies were responsible, etanercept being involved mainly in new onset uveitis.

Disclosure of Interest: None declared

DOI: 10.1136/annrheumdis-2018-eular.4071

\section{SAT0277 IMMUNOGENICITY AND LOSS OF RESPONSE TO TNF INHIBITORS IN AXIAL SPONDYLOARTHRITIS: RESULTS FROM AN OBSERVATIONAL COHORT STUDY}

C.I. Ancuta ${ }^{1}$, C. Pomirleanu' ${ }^{2}$, R. Paiu ${ }^{2}$, G. Strugariu ${ }^{2}$, L. Petrariu², E. Ancuta ${ }^{3}$, C. lordache ${ }^{1}$, R. Chirieac ${ }^{4} .{ }^{1}$ University of Medicine and Pharmacy Grigore T Popa lasi; ${ }^{2}$ Clinical Rehabilitation Hospital; ${ }^{3}$ Elene Doamna Clinical Hospital; ${ }^{4}$ Sanocare Medical Center, lasi, Romania

Objectives: We aimed to evaluate the immunogenicity of TNF- $\alpha$ inhibitors and to assess potential influence on serum drug levels and clinical efficacy in patients with axial spondyloarthritis (axSpA).

Methods: We performed a cross sectional observational cohort study in 87 consecutive axSpA receiving anti-TNFs (either for the first time or switched), followed-up in a single outpatient rheumatology department. Treatment with antiTNF agents was recommended in accordance with the local regulations on the initiation and continuation of biologics, as well as ASAS/EULAR guidelines.

Disease activity scores were assessed at baseline (V1) and study visit (V2), while drug trough levels and anti-drug antibodies were measured in serum samples (ELISA, Progenika) and collected before the next administration as a single-point data. Serum drug levels were considered positive if $>0.035 \mu \mathrm{g} / \mathrm{mL}$ IFX, $>0.024 \mu \mathrm{g} /$ $\mathrm{mL}$ ADL and $>0.035 \mu \mathrm{g} / \mathrm{mL}$ ETN, while the cut-offs for anti-IFX was $5 \mathrm{AU} / \mathrm{mL}$, antiADL $10 \mathrm{AU} / \mathrm{mL}$, anti-ETN $142 \mathrm{AU} / \mathrm{mL}$. Statistical analysis was performed using SSPS version 19.0, $\mathrm{p}<0.05$

Results: Among 150 axSpA treated with TNF inhibitors in our centre, 28 (32.18\%) receiving adalimumab (ADL), 19 (21.83\%) infliximab (IFX) and 40 (45.97\%) etanercept (ETN) were included in the immunogenicity analysis.

Only 11 patients (12.64\%) developed anti-drug antibodies, 8 under ADL $(28.57 \%)$ and 3 under IFX (15.78\%), with significant decrease in drug levels $(3.97 \mu \mathrm{g} / \mathrm{mL}$ vs. $0.07 \mu \mathrm{g} / \mathrm{mL}$ ADL, $\mathrm{p}<0.05 ; 1.82 \mu \mathrm{g} / \mathrm{mL}$ vs. $0.05 \mu \mathrm{g} / \mathrm{mL}$ IFX, $\mathrm{p}<0.05$ ) and impact on disease outcomes $(p<0.05)$

Higher disease activity scores (BASDAI, ASDAS-CRP) were reported in anti-drug positive axSpA irrespective of the background therapy $(p<0.05)$, with more patients classified as being in a high or very high disease activity status at V2. Furthermore, a relation between clinical improvement (change in ASDAS) and immunogenicity was reported: positive anti-drug antibodies axSpA achieved worse clinical response than negative anti-drug antibodies cases, with a significant association between ADL respectively IFX levels and ASDAS $(p<0.05)$.

No anti-drug antibodies were found in patients treated with ETN; significant higher persistence on ETA than under monoclonal antibodies was registered in our $\operatorname{axSpA}(\mathrm{p}<0.05)$.

Conclusions: Immunogenicity may impact disease outcomes and drug survival, particularly in the adalimumab and infliximab treated axSpA. Measuring anti-drug antibodies and serum drug levels may help to optimise therapeutic strategies in selected patients.

Disclosure of Interest: None declared

DOI: 10.1136/annrheumdis-2018-eular.2979

\section{SAT0278 NSAIDS REDUCES RADIOGRAPHIC PROGRESSION IN SACLOILIAC JOINTS IN EARLY AXIAL SPONDYLOARTHRITIS}

D. Rumiantceva ${ }^{1}$, T. Dubinina ${ }^{2}$, O. Rumyantseva ${ }^{1}$, A. Demina ${ }^{2}$, S. Erdes ${ }^{1}$. ${ }^{1}$ Laboratory of spondyloarthritis; ${ }^{2}$ Laboratory of scientific and organizational problems in rheumatology, V. A. Nasonova Research Institute of Rheumatology, Moscow, Russia, Moscow, Russian Federation

Background: According to the ASAS-EULAR management recommendations for axial spondyloarthritis (axSpA) patients (pts) suffering from pain and stiffness should use an NSAIDs as first-line drug and for pts who respond well to NSAIDs continuous use is preferred if symptomatic otherwise. Two studies have suggested that the continuous use of NSAIDs in patients with an elevated CRP results in reduced progression of structural damage in the spine in comparison to on-demand use. ${ }^{1 ; 2}$ But up-to-date the question of the effect of NSAIDs on radiographic progression in early axSpA remains open.
Objectives: To compare continuous and on-demand treatment groups on radiographic progression sacloiliac joints (SIJ) in axSpA.

Methods: The research included 68 pts with early axSpA ASAS criteria, ${ }^{2009}$ from Moscow CORSAR cohort with disease duration $<5$ years, age onset $<45$ years and at least 2 years follow up (FUP). $33(48,5 \%)$ males, pts mean age was 28,5 $(5,8)$ y., average disease duration - 24,1 $(15,4)$ mo, $63(92,6 \%)$ pts were HLA-B27 positive. Pts were randomised into two treatment groups: group 1 - continuous uses of NSAIDs; group 2 - on-demand uses of NSAIDs. The dosages of NSAIDs accounted by the ASAS NSAID index. At baseline 6 pts received TNF inhibitors, after 2 y. FUP 14 pts receives TNF inhibitors.

Results: No significantly differences in axSpA disease activity between two groups at baseline (table 1) and after 2 y. FUP (table 2). At group №1 8,2\% pts has radiographic progression in SIJ (from nr-axSpA to AS), at group №2\%-13,3\% pts $(p=0,000)$.

Abstract SAT0278 - Table 1. Outcome parameters at baseline.

\begin{tabular}{lccc}
\hline & $\begin{array}{c}\text { Group №1 } \\
(\mathrm{n}=31)\end{array}$ & $\begin{array}{c}\text { Group №2 } \\
(\mathrm{n}=31)\end{array}$ & $\mathrm{p}$ \\
\hline Ankylosing spondylitis, $\mathrm{n}, \%$ & $22(70,9 \%)$ & $15(50,0 \%)$ & 0088 \\
Non-radiographic axSpA, $\mathrm{n}, \%$ & $9(29,1 \%)$ & $17(50,0 \%)$ & 0257 \\
ASDAS CRP, Me, [25\%\%; 75\%o] & $2,5^{1,5 ; 3,5}$ & $2,3^{1,2 ; 2,7}$ & 0300 \\
BASDAl, Me, [25\%; 75\%o] & $4,0^{2,4 ; 5,1}$ & $2,8^{1,5 ; 4,4}$ & 0299 \\
CRP, Me, [25\%o; 75\%o] & $5,1^{1,7 ; 20,0}$ & $4,5^{1,0 ; 12,8}$ & 0648 \\
BASFI, Me, [25\%; 75\%o] & $1,4[0,5 ; 2,5]$ & $0,5[0,2 ; 1,7]$ & 0152 \\
Positive MRI of the SIJs, $\mathrm{n}, \%$ & $22(70,9 \%)$ & $15(50,0 \%)$ & 0088 \\
LEEDS score, Me, [25\%; & $1,0[0 ; 3,0]$ & $0,5[0 ; 2,0]$ & 0217 \\
75\%o] & & &
\end{tabular}

Abstract SAT0278 - Table 2. Outcome parameters after 2 years of NSAIDs treatment

\begin{tabular}{lccc}
\hline & $\begin{array}{c}\text { Group №1 } \\
(\mathrm{n}=24)\end{array}$ & $\begin{array}{c}\text { Group №2 } \\
(\mathrm{n}=30)\end{array}$ & $\mathrm{p}$ \\
\hline Ankylosing spondylitis, $\mathrm{n}, \%$ & $19(79,1 \%)$ & $19(63,3 \%)$ & 0201 \\
Non-radiographic axSpA, $\mathrm{n}, \%$ & $5(20,9 \%)$ & $11(36,7)$ & 0229 \\
ASDAS CRP, Me, [25\%o; 75\%o] & $1,2[0,9 ; 2,4]$ & $1,3[0,7 ; 2,1]$ & 0754 \\
BASDAI, Me, [25\%; $75 \%$ o $]$ & $2,1^{1,0 ; 3,0}$ & $1,8[0,9 ; 2,4]$ & 0553 \\
CRP, Me, [25\%; 75\%o] & $1,9[0,85 ; 11,3]$ & $1,3[0,6 ; 5,0]$ & 0292 \\
BASFI, Me, [25\%; 75\%o] & $0,4[0,1 ; 2,1]$ & $0,1[0 ; 0,4]$ & $\mathbf{0 , 0 0 9 7}$ \\
Positive MRI of the SIJs, $\mathrm{n}, \%$, & $8(33,3 \%)$ & $8(26,6 \%)$ & 0573 \\
LEEDS score, Me, [25\%; & $0[0 ; 1,0]$ & $0[0 ; 2,0]$ & 0571 \\
75\%o] & & & \\
NSAID index, Me, [25\%; 75\%o] & $100^{58,5 ; 100}$ & $28,5^{10,7 ; 75,0}$ & $\mathbf{0 , 0 0 1 2}$ \\
\hline
\end{tabular}

Conclusions: The frequency of NSAIDs treatment does not affect on the activity of axSpA. Continuouly uses of NSAIDs reduces radiographic progression in sacloiliac joints in pts with early axSpA.

\section{REFERENCES :}

[1] Wanders A, et al. Nonsteroidal antiinflammatory drugs reduce radiographic progression in patients with ankylosing spondylitis: a randomized clinica trial. Arthritis Rheum 2005;52:1756-65.

[2] Kroon F et al. Continuous NSAID use reverts the effects of inflammation on radiographic progression in patients with ankylosing spondylitis. Ann Rheum Dis 2012;71:1623-9.

Disclosure of Interest: None declared DOI: 10.1136/annrheumdis-2018-eular.1401

\section{SAT0279 COMPARISON OF RETENTION RATES BETWEEN TUMOUR NECROSIS FACTOR-A INHIBITORS IN ANKYLOSING SPONDYLITIS PATIENTS: DATA FROM THE KOREAN COLLEGE OF RHEUMATOLOGY BIOLOGICS REGISTRY}

E.H. Park ${ }^{1}$, S. Oh ${ }^{2}$, H.-A. Kim ${ }^{3}$, Y.-B. Park ${ }^{4}$, K. Shin ${ }^{2} .{ }^{1}$ Department of Internal Medicine (Division of Rheumatology), Seoul National University Hospital; ${ }^{2}$ Department of Internal Medicine (Division of Rheumatology), SMG-SNU Boramae Medical Center, Seoul; ${ }^{3}$ Department of Internal Medicine (Division of Rheumatology), Ajou University Hospital, Suwon; ${ }^{4}$ Department of Internal Medicine (Division of Rheumatology), Yonsei University College of Medicine, Severance Hospital, Seoul, Korea, Republic Of

Background: Drug persistence of tumour necrosis factor-a inhibitors (TNFi) tends to be higher in patients with ankylosing spondylitis (AS) than rheumatoid arthritis but there are few studies of Asian AS patients in the literature.

Objectives: To investigate drug retention rates of various TNFi used in Korean AS patients. 
Methods: Subjects were AS patients enrolled in the Korean College of Rheumatology Biologics registry KOBIO, Dec $2012 \sim$ ). All approved and commonly prescribed TNFi were included in the analysis. Discontinuation was defined as switching or stopping the biologic agent. Kaplan-Meier curve and Cox proportional hazard model were used for further analysis. Reason of TNFi discontinuation was also assessed. Univariate and multivariate analyses were used to identify possible predictors of discontinuation.

Results: Data of total of 1005 AS patients were analysed (median follow-up period: 14 months). The mean age of patients was 40.7 , and $77.4 \%$ were males. The mean disease duration was 7.1 years, HLA-B27 were positive in $82.4 \%$, and $33.2 \%$ of patients had lesion(s) of syndesmophytes. Seventy-six percent of patients were first-time biologic users. Discontinuation of TNFi occurred in $24.2 \%$ (switching in $9.6 \%$ ) of patients during follow-up. The drug survival function estimate showed that the adjusted hazard ratio (HR) of golimumab (compared with etancercept) was $0.441(95 \% \mathrm{Cl} 0.277-0.703, \mathrm{p}<0.001)$. The reason of discontinuation was inefficacy $(32.6 \%)$, adverse events (23.6\%), clinical improvement $(11.2 \%)$, and others (32.6\%). A multivariate analysis indicated predictors of discontinuation to be shorter disease duration ( $H R$ 0.973, $\mathrm{p}=0.044$ ), and negative HLA-B27 (HR 1.623, $p=0.0093$ ).

Conclusions: Our study demonstrates that few AS patients switched to other TNFi during their course of treatment. The drug retention rate of golimumab was higher compared with other agents prescribed in Korean AS patients.

Disclosure of Interest: None declared

DOI: 10.1136/annrheumdis-2018-eular.4988

\section{SAT0280 RAPAMYCIN RESTORES THE BALANCE BETWEEN TH17 AND REGULATORY T CELLS IN USPA PATIENTS}

F. Jinnan ${ }^{1}$, X. Dan ${ }^{1}$, G. Chong ${ }^{2}$, L. Xiaofeng ${ }^{1} .{ }^{1}$ The Second hospital of Shanxi Medical University, Taiyuan, China; ${ }^{2}$ Brigham and Women's Hospital, Boston, USA

Background: The association of undifferentiated spondyloarthritis (uSpA) with the imbalance of Th17/Treg cells is still unclear. By inhibiting mTOR, rapamycin promotes the proliferation of Treg cells and inhibits the growth of Th17 cells.

Objectives: Therefore, we aimed to investigate the status of Treg and Th17 cells in uSpA patients and explore the therapeutic effect of Rapamycin on uSpA patients with imbalanced of Th17 and Treg cells.

Methods: Two hundred thirty-seven new onset uSpA patients and 93 healthy controls were enrolled. These patients fulfilled ESSG criteria for SpA but did not fulfill the criteria for any established disease of the group. Both absolute numbers and proportions of Treg (CD4 +CD25+Foxp3+T) and Th17 (CD4 + IL-17+T) cells in peripheral blood were analysed by flow cytometry. The 21 new onset Patients with imbalance of Th17/Treg cells were treated with rapamycin at a dose of $0.5 \mathrm{mg}$ twice for a weeks or every 2 days for 6 weeks combined with conventional treatment (salazosulfapyridine $500 \mathrm{mg}$ three times per day; etoricoxib $60 \mathrm{mg}$ once per day or other NSAIDs drugs).

Results: Increase in absolute number and percentage of Th17 (Th17\% 1.11 \pm 0.66 vs $2.43 \pm 1.21, p<0.05$; Th17 cells/ $\mu$ l 7.54 \pm 4.07 vs $19.54 \pm 18.45, p<0.05$ ) and decrease in those of Tregs (Treg\% $4.8 \pm 1.60$ vs $3.35 \pm 1.76, p<0.05$; Treg cells $/ \mu$ l (33.77 \pm 13.67 vs $27.79 \pm 28.62, p<0.05)$ were found in $18.6 \%(44 / 237)$ of patients with $\mathrm{uSpA}$ as compared with that of healthy controls. The patients with imbalance of Th17/Treg cells displayed higher BASDAI scores and ESR as compared with other uSpA patients [BASDAI $(3.27 \pm 1.06$ vs $1.13 \pm 0.91 \mathrm{P}<0.05)$; ESR (29.27 \pm 19.32 vs $21.80 \pm 18.34 \mathrm{P}<0.05)]$. The absolute count of Th17 in 21 patients received rapamycin reduced after 6 weeks $(12.35 \pm 11.00$ vs $6.69 \pm 5.54, p<0.05)$ whereas that of Treg cells showed increase trend but the difference did not reach statistical significance.

Conclusions: Absolute number of Treg decreased and that of Th17 cells increased in the peripheral blood of uSpA patients, suggesting that imbalance of the two subsets contributes to the pathogenesis of uSpA. Rapamycin recovered the balance between Th17 and Treg cells in uSpA patients by reducing Th17 cells.

\section{REFERENCES:}

[1] Cruzat V, et al. Undifferentiated spondyloarthritis: recent clinical and therapeutic advances. J. Curr Rheumatol Rep 2010 Oct;12(5):311-317.

[2] da Cruz Lage R, et al. Undifferentiated spondyloarthritis in a heterogeneous Brazilian population: an eight-year follow-up study. J. Rheumatol Int 2014 Jul;34(7):1019-1023.

[3] Heather K, et al. Rapamycin inhibits differentiation of Th17 cells and promotes generation of FoxP3+ $\mathrm{T}$ regulatory cells. J. Int Immunopharmacol 2007 Dec;15;7(13):1819-1824

[4] Raychaudhuri SP, et al. IL-23/IL-17 axis in spondyloarthritis-bench to bedside. J. Clin Rheumatol 2016 Jun;35(6):1437-1441.

Disclosure of Interest: None declared

DOI: 10.1136/annrheumdis-2018-eular.4133

\section{SAT0281 BIOLOGICS IN SAPHO SYNDROME. A SYSTEMATIC REVIEW}

D. Daoussis, G. Konstantopoulou, I. Antonopoulos, S.-N. Liossis. Rheumatology, University of Patras Medical School, Rio, Patras, Greece

Background: The SAPHO (Synovitis, Acne, Pustulosis, Hyperostosis, Osteitis) syndrome is a relatively rare clinical entity characterised by a wide range of dermatological and musculoskeletal manifestations. Treatment is largely empiric since guidelines do not exist. Biologics have been used in cases refractory to conventional treatment.

Objectives: To systematically review all cases of patients with SAPHO syndrome treated with biologics to date.

Methods: We performed a systematic electronic search (PubMed) using the key words SAPHO combined with any of the following: treatment, biologics, anti-TNF infliximab, adalimumab, etanercept, certolizumab, golimumab, IL-1, anakinra, canakinumab, IL-17, secukinumab, IL-23, ustekinumab, IL-6, tocilizumab, abatacept, rituximab. The only limit set was English language. The computerised search was supplemented by a manual one on the reference lists of the retrieved articles.

The search identified 461 articles; the abstracts of these articles were assessed in order to identify studies related to the therapeutic use of biologics in patients with SAPHO syndrome. Only 36 articles fulfilled the search criteria and were included in the analysis.

Results: We identified 64 cases treated with biologics (44 with TNF blockers, 7 with IL- 1 blockers, 12 with biologics targeting the IL-23/IL-17 axis and 1 with tocilizumab). Data support a positive effect of anti-TNF treatment in SAPHO with a response rate in bone and joint manifestations of $95.4 \%$. Skin disease also improved in $21 / 29$ cases (response rate $72.4 \%$ ). Data related to IL-1 inhibition in SAPHO are encouraging with most patients (6/7) exhibiting a significant response in musculoskeletal manifestations (response rate 85.7\%). However, IL-1 inhibition is not effective in skin manifestations. Ustekinumab seems to have some efficacy with $2 / 4$ patients responding in skin and $3 / 5$ in bone/joint manifestations. Data related to IL-17 blockade indicate efficacy in skin disease with $4 / 7$ patients responding (response rate $57.1 \%$ ). Joint/bone manifestations improved in $2 / 7$ patients (response rate $28.6 \%$ ).

Conclusions: In SAPHO patients not responding to conventional treatment, TNF blockers should be the first choice. In patients failing TNF blockers, IL-1 inhibitors and biologics targeting the IL-17/IL-23 axis could be used.

Disclosure of Interest: None declared

DOI: 10.1136/annrheumdis-2018-eular.4186

\section{SAT0282 OCCURRENCE OF ANTERIOR UVEITIS IN PATIENTS WITH SPONDYLOARTHRITIS AND PSORIATIC ARTHRITIS TREATED WITH TUMOUR NECROSIS FACTOR INHIBITORS: A RESTROSPECTIVE MONOCENTRIC STUDY COMPARING THE SOLUBLE RECEPTOR TO THE MONOCLONAL ANTIBODIES}

G. Khoury ${ }^{1}$, B. Combe ${ }^{1}$, J. Morel ${ }^{1}$, C. Lukas ${ }^{2} .{ }^{1}$ Rheumatology, Hopital Lapeyronie; ${ }^{2}$ Rheumatology, Hop Lapeyronie, Montpellier Cedex 5, France

Background: The efficacy of tumour necrosis factor inhibitors against anterior uveitis has been shown, but discrepancies remain as to the difference in efficacy between soluble receptor and monoclonal antibodies.

Objectives: The objective of this study was to compare the occurrence of anterior uveitis with soluble receptor and monoclonal antibodies in patients with spondyloarthritis (SPA) and psoriatic arthritis (PA).

Methods: This was an observational, retrospective, monocentric study. Patients attending the rheumatology department of the Montpellier University Hospital for a SPA or a PA and who were prescribed anti-TNF agents between 2000 and 2014 were included in our cohort. Data on the diagnosis of rheumatism, the history of the disease and the extra-articular symptoms were collected from medical records. The risk of uveitis has been interpreted qualitatively (number of subjects with at least one flare of uveitis) and quantitatively (number of uveitis flares for each patient). Logistic regression models were used for qualitative analyses and Poisson models for quantitative analyses.

Results: 429 patients were included ( 302 with SPA and 127 with PA, 203 were treated with a monoclonal antibody as first TNF alpha inhibitor and 226 with the soluble receptor). No difference between monoclonal antibodies and soluble receptor was found in the risk of uveitis occurring during the first year of treatment $(\mathrm{OR}=0.94$ [0.35; 2.54], $\mathrm{p}=0.90$ in qualitative analysis and $\mathrm{R}=0.62[0.26 ; 1.46]$; $\mathrm{p}=0.27$ in quantitative analysis). The risk of uveitis was higher with the soluble receptor for the first-line TNF inhibitors, as well as for all therapeutic lines, but this difference was not statistically significant ( $p=0.09$ and 0.08 respectively in quantitative analysis and 0.68 and 0.53 in quantitative analysis).

Conclusions: In view of our observations, the risk of uveitis does not appear to be significantly higher with the soluble receptor than with the monoclonal 